Case Reports

Juntendo Medical Journal

2015. 61 (3), 302-304

\title{
Azuki Bean Allergy in a Japanese Child: a Case Report
}

\author{
KIYOTAKA OHTANI*, MAYU FUJIMOTO*, Hitomi INAGAKI*, \\ KAZUTERU KITSUDA*, MASAKo KITSUNEZAKI*, ShINya NAKAMURA* \\ *Department of Pediatrics, Sagamihara Kyodo Hospital, Kanagawa, Japan
}

Background: Azuki bean is sometimes a nutritional alternative for those with soybean allergy. Although soybean and peanut are relatively common food allergens, azuki bean allergy has not previously been reported.

Case Report: A 3-year-old male was referred for investigation of suspected azuki bean allergy. He developed urticarial lesions within 30 min after eating an azuki bean product (manju, a sort of Japanese sweet), with a similar episode reported 1 year prior. The total serum immunoglobulin E ( $\mathrm{IgE}$ ) level was $677 \mathrm{IU} / \mathrm{m} l$, with elevated specific IgE antibodies (ImmunoCAP) to soybean, peanut, kidney bean, and pea. Azuki bean specific IgE antibodies are not available, currently. The wheals produced by skin prick test (SPT) were boiled azuki bean without sugar $5 \mathrm{~mm}$, yohkan (a typical Japanese sweet) $8 \mathrm{~mm}$, sweetened azuki bean paste 7 $\mathrm{mm}$, and soybean $4 \mathrm{~mm}$. Double-blind placebo-controlled food challenge (DBPCFC) with azuki bean without sugar induced urticaria after $60 \mathrm{~min}$, which resolved after oral antihistamine administration. He did not develop symptoms after ingestion of control.

Conclusions: This is the first reported case of immediate-type azuki bean allergy, diagnosed by SPT and DBPCFC. Further study such as immunoblotting is needed to elucidate the specific allergenic antigen.

Key words: azuki bean, food allergy, immunoglobulin E, double-blind placebo-controlled food challenge, skin prick test

\section{Abbreviations}

IgE: immunoglobulin $\mathrm{E}$

DBPCFC: double-blind placebo-controlled food challenge

rGly m: recombinant Glycine max

SPT: skin prick test

\section{Background}

The azuki bean (Vigna angularis) is thought to have originated in East Asia, and has been eaten in Japan since ancient times. The seed coat of the azuki bean contains polyphenols, including antioxidants such as anthocyanins, rutin, and catechin ${ }^{1}$, which have been recommended as a natural means of combating diabetes and obesity ${ }^{2)}$. The Japanese Guideline for Food Allergy recommends other beans as nutritional alternatives for patients with soybean allergy. However, some patients may also develop symptoms of allergy after ingestion of other beans ${ }^{3)}$. The current case study is the first reported case of immediate-type azuki bean allergy in a Japanese child, which was diagnosed by skin prick test (SPT) and a double-blind placebo-controlled food challenge (DBPCFC).

\section{Case report}

A 3-year-old male was referred to our hospital for investigation of suspected azuki bean allergy. He recently developed a few urticarial lesions within 30 min after eating an azuki bean product (manju, a sort of Japanese sweet), and his parents reported a similar episode about 1 year prior. And when he ingested azuki bean, he has been always observed immediate reactions. The urticaria was not associated with symptoms indicating viral infection or other disease. He was otherwise healthy, with no history of atopic dermatitis, asthma, or allergic rhinitis. There was no prior history of allergic reaction to the other ingredients of the azuki bean product, or to other legumes such as black-eyed

Corresponding author: Kiyotaka Ohtani

Department of Pediatrics, Sagamihara Kyodo Hospital

2-8-18 Hashimoto, Midori-ku, Sagamihara-City, Kanagawa 252-5188, Japan

TEL: +81-42-772-4291 FAX: +81-42-771-6709 E-mail: k-ootani@sagamiharahp.com

[Received Dec. 8, 2014] [Accepted Feb. 4, 2015] 
Table-1 Levels of specific IgE (ImmunoCAP)

\begin{tabular}{lccc}
\hline & $\begin{array}{c}\text { Specific IgE } \\
\left(\mathrm{kU}_{\mathrm{A}} / l\right)\end{array}$ & & $\begin{array}{c}\text { Specific IgE } \\
\left(\mathrm{kU}_{\mathrm{A}} / l\right)\end{array}$ \\
\hline House dust mite & 1.49 & Soybean & 42.4 \\
Cedar & 40.5 & Peanut & 9.03 \\
Japanese alder & $<0.10$ & Kidney bean & 70.9 \\
Ragweed & 0.13 & Pea & 21.9 \\
Orchard grass & $<0.10$ & rGly m 4 & $<0.10$ \\
Wheat & 2.43 & rGly m 5 & 19.6 \\
$\omega-5$ gliadin & $<0.10$ & rGly m 6 & 6.74 \\
Gluten & 0.48 & & \\
\hline
\end{tabular}

Normal range for ImmunoCAP: $<0.35 \mathrm{kU}_{\mathrm{A}} / l$.

Table-2 Skin prick test

\begin{tabular}{lcc}
\hline & $\begin{array}{c}\text { Diameter of wheal } \\
(\mathrm{mm})\end{array}$ & $\begin{array}{c}\text { Diameter of erythema } \\
(\mathrm{mm})\end{array}$ \\
\hline Azuki bean paste without sugar & 5 & 8 \\
Yohkan (a typical Japanese sweet) & 8 & 16 \\
Sweetened azuki bean paste & 7 & 15 \\
Black-eyed pea paste without sugar & 4 & 8 \\
Soybean & 4 & 7 \\
Peanut & 5 & 19 \\
Wheat & 2 & 4 \\
Positive control & 8 & 13 \\
Negative control & 2 & 4 \\
\hline
\end{tabular}

Positive control: histamine dihydrochloride $(10 \mathrm{mg} / \mathrm{m} l)$, negative control: $0.9 \%$ normal saline.

pea, soybean, peanut, kidney bean, or pea.

Physical examination showed a healthy child with normal vital signs. Examination of the head and neck, chest, abdomen, and skin were normal. Laboratory examinations showed a white blood cell count of 13,700/ $\mu l$ (normal range: 7,000-11,000/ $\mu l$ ) with 3.5\% eosinophils (normal range: 0-8\%). Serum total immunoglobulin E (IgE) levels were $677 \mathrm{IU} / \mathrm{m} l$ (normal: < 170). Specific IgE $\left(\mathrm{kU}_{\mathrm{A}} / l\right)$ (ImmunoCAP; Phadia $\mathrm{AB}$, Uppsala, Sweden) showed elevated levels of specific IgE antibodies to soybean (42.4), peanut (9.03), kidney bean (70.9), pea (21.9), recombinant Glycine max (rGly m) 5 (19.6), and rGly m 6 (6.74) (normal range: all $<0.35 \mathrm{kU}_{\mathrm{A}} / l$; Table-1). Azuki bean specific $\mathrm{IgE}$ antibodies are not available, currently.

SPT was performed using commercially available allergens for soybean, peanut, and wheat (Torii Pharmaceutical Co., Ltd., Tokyo, Japan), as well as boiled azuki bean without sugar, yohkan (a typical Japanese sweet) and sweetened azuki bean paste (azuki beans and sugar). The wheal for boiled azuki bean without sugar was $5 \mathrm{~mm}$, yohkan $8 \mathrm{~mm}$, sweetened azuki bean paste $7 \mathrm{~mm}$, black-eyed pea paste without sugar $4 \mathrm{~mm}$, soybean $4 \mathrm{~mm}$, peanut 5 $\mathrm{mm}$, and positive control $8 \mathrm{~mm}$ (Table-2). A wheal half diameter larger than that of the positive control was considered to indicate a positive test ${ }^{4)}$. The boiled azuki bean and azuki bean paste that were utilized in the SPT were azuki bean products of similar cooking method that has been ingested in DBPCFC.

After obtaining written informed consent from the parents, a DBPCFC was performed with azuki bean paste without sugar and black-eyed pea paste without sugar as a control. In view of the possibility of Maillard reaction, DBPCFC was performed using beans without sugar ${ }^{5)}$. At $60 \mathrm{~min}$ from the start of the DBPCFC, he had facial flushing and urticaria over his left axilla and flank. This was considered to indicate a positive reaction, and oral epinastine hydrochloride was administered. In contrast, he did not develop symptoms after ingestion of the control, and the patient was diagnosed with immediate-type azuki bean allergy based on the DBPCFC. No further symptoms were observed after elimination of azuki beans from his diet.

\section{Discussion}

To our knowledge, this is the first reported case of azuki bean allergy. The azuki bean belongs to the Fabaceae (legume) family, which also includes the soybean, black-eyed pea, kidney bean, pea, and peanut. Patients with allergy to one food in this family may also have cross-reactivity to other foods in the same family. In our patient, SPT and specific $\operatorname{IgE}$ showed elevated reactivity to soybean, pea, peanut, and kidney bean. However, he was able to eat soybeans, black-eyed peas, peas, kidney beans, and peanuts without clinical signs of allergy. As azuki bean specific IgE antibodies are not available, we performed SPT, which was positive. In addition, a DBPCFC induced symptoms of allergy.

As the patient had no history of rhinitis or eczema, he was diagnosed with probable type 1 food allergy caused by previous intestinal tract sensitization $^{6)}{ }^{7)}$. A type 2 food allergy associated with hay fever was considered unlikely because the symptoms occurred after ingestion of cooked azuki bean products. The specific antigen causing this allergy 
is unknown, and specific antigen testing for azuki bean allergy is not currently available. Previous studies reported that the levels of specific $\operatorname{IgE}$ antibodies to rGly $\mathrm{m} 5$ and rGly $\mathrm{m} 6$ were useful indicators for the severity of soybean allergy ${ }^{89} 9$. Although our patient had elevated levels of specific IgE antibodies to rGly $\mathrm{m} 5$ and rGly $\mathrm{m}$, he could ingest soybeans without clinical signs of allergy. The azuki bean and soybean might have different antigens that cause cross-reactivity in these examinations, and have involved other components.

This case could not be identified the antigen protein that was included in the azuki bean, also potentially intolerance for the components contained in the azuki bean could not be negative. Further study such as immunoblotting is needed to elucidate the specific allergenic antigen of the azuki bean.

\section{Conclusions}

This case is the first reported case of immediate-type azuki bean allergy diagnosed by SPT and DBPCFC in a Japanese child, without clinical allergy reaction to other foods from the Fabaceae family. It is important to recognize the possibility of azuki bean allergy, as azuki bean is sometimes recommended as a nutritional alternative for patients with soybean allergy. Further study such as immunoblotting is needed to elucidate the specific allergenic antigen of the azuki bean.

\section{Acknowledgments}

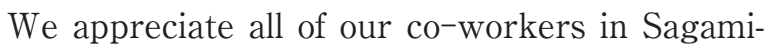

hara Kyodo Hospital.

\section{Conflict of interest}

The authors have no conflicts of interest to declare.

\section{References}

1) Mukai Y, Sato S: Polyphenol-containing azuki bean (Vigna angularis) seed coats attenuate vascular oxidative stress and inflammation in spontaneously hypertensive rats. J Nutr Biochem, 2011; 22: 16-21.

2) Preuss HG, Bagchi D, Bagchi M: Protective effects of a novel niacin-bound chromium complex and a grape seed proanthocyanidin extract on advancing age and various aspects of syndrome X. Ann N Y Acad Sci, 2002; 957: 250-259.

3) Urisu A, Ebisawa M, Mukoyama T, Morikawa A, Kondo $\mathrm{N}$ : Japanese guideline for food allergy. Allergol Int, 2011; 60: $221-236$.

4) Hill DJ, Hosking CS, Reyes-Benito LV: Reducing the need for food allergen challenges in young children: a comparison of in vitro with in vivo tests. Clin Exp Allergy, 2001; 31: 1031-1035.

5) Maleki SJ, Chung SY, Champagne ET, Raufman JP: The effects of roasting on the allergenic properties of peanut proteins. J Allergy Clin Immunol, 2000; 106: 763-768.

6) Ma S: A survey on the management of pollen-food allergy syndrome in allergy practices. J Allergy Clin Immunol, 2003; 112: 784-788.

7) Valenta R, Kraft D: Type 1 allergic reactions to plantderived food: a consequence of primary sensitization to pollen allergens. J Allergy Clin Immunol, 1996; 97: 893895.

8) Holzhauser T, Wackermann O, Ballmer-Weber BK, et al: Soybean (Glycine max) allergy in Europe: Gly $\mathrm{m} 5$ (beta-conglycinin) and Gly m 6 (glycinin) are potential diagnostic markers for severe allergic reactions to soy. J Allergy Clin Immunol, 2009; 123: 452-458.

9) Ito K, Sjolander S, Sato S, et al: IgE to Gly $m 5$ and Gly m 6 is associated with severe allergic reactions to soybean in Japanese children. J Allergy Clin Immunol, 2011; 128: 673-675. 